\title{
Teaching in Virtual Worlds: Opportunities and Challenges
}

\author{
Stacy Kluge \\ Georgia Southern University, \\ Statesboro, Georgia, USA
}

skluge@georgiasouthern.edu

\author{
Liz Riley \\ Macon State College, Macon, \\ Georgia, USA
}

liz.riley@maconstate.edu

\begin{abstract}
How, where, when, and what we teach has been significantly influenced by technological innovation. Radio, television, and computers have all altered how information is presented and how students interact with that information. This paper describes how virtual worlds provide a mechanism to incorporate constructivist, experiential, and student-centered learning practices into the classroom. The authors also discuss the challenges and the benefits of using virtual worlds in education as well as some implications for the fut ure of education.
\end{abstract}

Keywords: virtual worlds, Second life, constructivist learning, authentic learning, metaverse, Sloodle

\section{Introduction}

Jennifer James (1997) identified technology as one of four primary societal influencers that will have a significant impact on the fut ure. This societ al influence will usher in a period of rapid, technological change to which society, and it follows, its educational systems, will have to adapt. According to Polka (1999) educational technologies will have a profound impact on curriculum and on teaching and learning methodologies in the new millennium. These educational visionaries could not have been more correct. Technological change and innovation have greatly altered both what is taught and how educators teach. In order to survive, colleges will have to rethink where, what, when and how students learn.

In reconsidering how students learn, there are many significant changes to be made. Instead of using the centralized-control model where the instructor acts as a "sage on the stage" delivering information to a classroom of students, educators need to move to a more pluralistic and entrepreneurial approach to learning, where students take a much more active and independent role. Under this model the instructor acts more as a facilitator than as a chief executive. Students will be encouraged to work collaboratively, forming learning communities where each participant is

Material published as part of this publication, either on-line or in print, is copyrighted by the Informing Science Institute. Permission to make digital or paper copy of part or all of these works for personal or classroomuse is granted without fee provided that the copies are not made or distributed for profit or commercial advantage AND that copies 1 ) bear this notice in full and 2) give the full citation on the first page. It is permissible to abstract these works so long as credit is given. To copy in all other cases or to republish or to post on a serveror to redistribute to lists requires specific permission and payment of a fee. Contact Publisher@ InformingScience.org to request redistribution permission. both a teacher as well as a learner. Curriculum may also become more interdisciplinary, encouraging students to explore "rich connections among different domains of knowledge." (Kirkman, Cornelius, Sachs, \& Schwab, 2002, p. 36)

In rethinking what people learn, curricula should be updated to incorporate the instructional technologies that are avail- 
able today. Much of what students learn today is still based on old technologies of instruction; paper-and-pencil, chalk, and blackboard. Digitaltechnologies not only change what students should learn, but what students can learn. Ideas, topics, and experiences can be explored using digit al technologies. These would have been too difficult to represent with text books, blackboards, and chalk. Additionally, digital technologies allow leamers to explore many more domains of knowledge in greater depth. As the amount of easily accessible information grows at an astounding rate, institutions will have to focus less on imparting information and more on teaching students how to access necessary information (Kirkman et al, 2002).

Finally, and perhaps most importantly, we need to transform curricula so that they focus less on 'things to know' and more on 'strategies for learning the things you don't know.' As new technologies continue to quicken the pace of change in all parts of our lives, learning to become a better learner is far more important than learning to multiply fractions or memorizing the capitals of the world. (Kirkman et al, 2002, p. 36)

In rethinking where and when people learn, educat ors must recognize that schools “....are just part of a broader learning ecosystem. In the digital age, learning can and must become a daylong and lifelong experience." (Kirkman et al, 2002, p. 36) Leaming has become an activity where location is increasingly less important. Learning is no longer limited to a building with four walls, but can take place anytime, anywhere, facilitated by increasingly ubiquitous digital information and communication technologies. Colleges "should aim to improve learning opport unities not only in schools, but also in homes, community centers, museums, and workplaces." (Kirkman et al, 2002, p. 36)

\section{Significance of Virtual Worlds}

The emergence of online virtual worlds, three-dimensional environments where individuals are represented by avatars, poses many exciting opport unities as well as challenges for educators. These online virtual worlds, imagined and created by their inhabitants, are often referred to as "metaverses." Metaverses include aspects of the real world represented in virtual spaces. (Metaverse RoadMap Glossary, 2007). In many virtual worlds or metaverses residents have the freedom to design their avatars, create their environments, and to function in ways that mirror the real world. The freedom also exists to create experiences that diverge wildly from the real world. Some examples of these experiences include flying, walking underwater, or teleporting to various locations.

These virtual worlds have developed "through the convergence of social net working, simulation and online gaming." (Gartner Research, 2007). Some virtual worlds exist for the purpose of playing a game. Some virtual worlds have many games included as part of the world. However, "the concept of a virtual world does not require the elements of a game, such as rules or an explicit objective." (EDUCAUSE Learning Init iative, 2006, p. 1)

The popularity of virtual worlds has increased rapidly in recent years. Linden Lab's "Second Life", one of the leading virtual worlds, has grown from 230,000 residents in April of 2006 to 8.5 million residents in August of 2007 (Calongne \& Bayne, 2007). Gartner Research (2007) predicts that 80 percent of active Internet users will be taking part in virtual worlds by the end of 2011.According to the New Media Consortium and EDUCAUSE Learning Initiative 2007 Horizon Report,

Campuses and businesses have established locations in these worlds, much as they were creating websites a dozen years ago. In the same way that the number and sophistication of websites grew very quickly as more people began to 
browse, virtual locations will become more common and more mat ure as the trend continues."(p. 18)

There are some people that are even predicting that virtual worlds will redefine the Internet;

It would be far too simple to say that the Metaverse will consist of Linden Lab's virtual world with maps or Google's mirror world with avatars. What's coming is a larger digital environment combining elements of all these technologies - a 3-D Internet. (Rouse, 2007, p. 43)

While Gartner and others recognize the growth in virtual worlds, they also recommend that organizations proceed with caution. Organizations " ...should experiment with virtual worlds, but not plan massive projects." Additionally, Gartner advises organizations to "... limit substantial financial investments until the environments stabilize and mature." (Gartner, 2007)

It is not surprising that early adopters of innovative teaching and learning technologies in higher education are already adapting this environment for educational purposes. Currently there are over 100 institutions from over 18 countries, ranging from community colleges to Harvard Law School, that have a registered presence in Second Life (Institutions and organizations in Second Life, 2007). There are likely many other inst it utions participating in a less official fashion. Although still at a very early and somewhat immat ure stage, educators are experimenting with creating educational programs using virtual worlds (EDUCAUSE Learning Initiative, 2006, p. 1).

Virtual worlds provide a new range of educational opportunity. The nat ure of these environments is generative, allowing users not only to navigate and interact with a pre-existing three-

dimensional environment, but also to extend that environment by creating objects of their own.

These objects can be seen and used by others. Although the user is ultimately constrained by the technologies driving the virtual world, each virtual world offers a set of tools for recreating real world objects and experiences and for expanding these objects and experiences as far as the imagination and technology can reach. This paper focuses on some of the opport unities and challenges posed by adapting virtual worlds for educational use.

\section{Opportunities for Education using Virtual Worlds}

Virtual worlds can be very effective learning spaces. The environment is generalized ratherthan contextual which allows virtual worlds to be applicable to almost all disciplines.

Settings can be created to pertain to any subject or area of study; locations and artifacts can be as realistic and detailed, or as generic and undefined as desired. $3 \mathrm{D}$ construction tools allow easy visualization of physical objects and materials, even those normally occurring at cosmic or nano scales. (New Media Consortium, 2007, p. 18)

The primary distinguishing factor between virtual worlds and other Web 2.0 applications is their generative capabilities. Users can create three dimensional objects that can be seen and used by the person that created the object as well as other users in the virtual world. Second Life, for example, has an internal building system that begins with geometric shapes, such as cubes, cones, and cylinders, called "prims". Users can stretch "prims" into new shapes and link prims to create new objects. The system allows users to import textures stored as JPEG files and other formats and apply them to objects to give a more rich and realistic appearance. Second Life also has an internal script ing language that allows users to create and assign behaviors to objects. The internal building system and scripting language allow educat ors to create simple or elaborate learning environments and 3-D interactive manipulatives for students. Residents maintain intellectual property rights to their creations. Additionally the user's avat ar can be highly customized. Character type (human, animal, etc), gender, body characteristics, hair, facial appearance, and clothes 
can all be readily changed. Students communicate in the Second Life "world" via chat, instant messaging, and voice over IP which requires a headset and microphone.

Virtual worlds present an opportunity for faculty to move from a teacher-centered to a studentcentered model of instruction. According to Polka (2001), it is vital that inst it utions migrate from using a teacher-centered model of instruction to a student-centered model. Student-centered models of instruction often incorporate constructivist learning theories in which learners "use their experiences to actively construct understanding that makes sense to them, rather than have understanding delivered to them in already organized form." (Polka, 2001, p.55) In virtual worlds students are actively engaged and constantly in the process of constructing meaning from their experiences. Additionally, "virtual worlds offer an opport unity for people to interact in a way that conveys a sense of presence lacking in other media." (New Media Consortium, 2007, p. 18) Virtual worlds present an excellent opportunity for educators to implement learner-centered pedagogies that promote active, constructivist, and inquiry or problem-based pedagogies. They “...hold significant potential for learner-led - rather than an outcome based - model of exploration and knowledge development." (EDUCAUSE Learning Initiative, 2006, p. 1)

Virtual worlds can be adapted to implement authentic learning strategies.

Authentic learning typically focuses on real-world, complex problems and their solutions, using role-playing exercises, problem-based activities, case studies, and participating in virtual communities of practice. The learning environments are inherently multidisciplinary. They are not constructed in order to teach geometry or to teach philosophy. A learning environment is similar to some 'real world' application or discipline: managing a city, building a house, flying an airplane, setting a budget, solving a crime, for example.(Lombardi, 2007, p.2).

In the past, authentic learning activities have been difficult to implement. Some activities are too costly, complex, or even dangerous to perform in the classroom; some are not possible at all. Virtual worlds, however, are allowing simulations and activities to take place in a manner that closely resembles read-world situations.

These worlds lend themselves to role playing and scenario building, allowing learners to temporarily assume the responsibilities of an astronomer, chemist, or engineer without incurring real-world consequences...Simulated problem-solving activities can be planned in custom settings like a hospital room, a power plant, or even an entire town." (New Media Consortium, 2007, p. 18-19)

Games and simulations which take place in virtual worlds require the active participation and engagement of the student. Learners simply cannot be passive while playing a game or participating in a simulation.

Students engaged in educational games and simulations are interpreting, analyzing, discovering, evaluating, acting, and problem solving. This approach to learning is more consistent with constructivist learning, where knowledge is constructed by the learners as they are actively problem solving in an authentic context, than with traditional instruction. (Antonacci \& Modaress, 2005, p.4)

Active participation or "learning by doing" is a model favored by both students and many educators, especially those of the "gaming generation". Virtual worlds provide a means of creating models of this nature. "Virtual worlds and authent ic learning activities foster unintentional learning, where students discover and create knowledge not for its own sake but in order to accomplish something they want to do, result ing in stronger comprehension and deeper knowledge." (EDUCAUSE Learning Initiative, 2006, p. 1) 
Collaboration is an important aspect of creating knowledge and meaning (Antonacci \& Modaress, 2005). Virtual environments allow multiple learners to communicate and collaborate on the same issue or problem. Students frequently form learning communities "who interact socially to discuss strategies, share experiences, and provide encouragement via websites, discussion boards, blogs, and wikis" (Antonacci \& Modaress, 2005, p.5). It is thought that virtual worlds will continue this trend seen in earlier technologies. Additionally, virtual worlds may facilitate collaboration by providing a means of communication that is more like face-to-face communication than other popular technologies such as email, blogs, and wikis.

Virtual worlds provide an environment wherein educators can prepare learners for "the increasingly complex and interconnected global society in which they live and work" (Moore, Fowler, \& Watson, 2007, p. 46). Students across the globe can easily interact using virtual worlds. For example, it is not unusual to visit Second Life and meet someone that speaks a language other than one's native tongue. Some of these virtual worlds also have their own economy, thus providing students with the challenge of surviving in situations where the exchange of goods and services may not follow the 'norm' with which they are accustomed. Simply observing the variety of clothing, facial features, and dress of avatars in virtual worlds offers students the opport unity to learn about their reactions to the visual qualities of people.

\section{Challenges of Education with Virtual Worlds}

From a student's perspective there are many challenges to virtual worlds. Participation in virtual worlds requires robust hardware and a broad band Internet connection. Some students, classrooms, or computer labs may not have computers that meet the minimum or recommended specification for optimal use of virtual worlds. Virtual worlds also make little effort to meet standards for accessibility. For example, virtual worlds do not work with screen readers, limiting their accessibility to the visually impaired. Some students may find the world so engaging that they get distracted from course goals. At the extreme this may result in lack of participation or inappropriate behavior. Students enrolled in technology-related programs may feel more comfortable with technical aspects of virtual worlds such as creating and scripting objects, whereas students from less technical disciplines may find simple navigation daunting.

Teaching in virtual worlds also presents a list of challenges. Creating classes in a virtual world requires skills that most educators don't have. The development time for courses is far beyond what is 'normally' required. For certain courses that have very specific learning objectives, the effort involved in designing a virtual environment is not justified (EDUCAUSE Learning Initiative, 2006, p. 1).

Cost is another issue. Second Life, for example, offers several membership plans. The basic account is free, enabling students to participate at no cost. However, for an institution to create a presence in Second Life and have a permanent area devoted to its educational activities, it must upgrade to a premium account which costs $\$ 9.99$ per month. A premium account is required to purchase land, which is necessary to create a sustained and safe learning environment for students. In order to restrict access and to accommodate multiple classes, institutions must purchase a private island. An island consists of 16 virtual acres and costs $\$ 1675$ with monthly maintenance fees of $\$ 295$ per island. This fee structure may be cost prohibitive for many schools until proof of concept. There is a 50\% discount available to educat ors on land purchases, but monthly maintenance fees are not discounted. (“Memberships," 2007)

Liability issues are still at question in virtual worlds. In Second Life private land can be purchased. Private land can be restricted to only authorized users, however, students in public areas may be subjected to sex, violence, or disruptive players (LaChapelle, 2007). There are many unresolved legal issues surrounding virtual violence, virtual assault, and sexual harassment that take 
place in Second Life and in other virtual worlds. Is a faculty member or administrat or liable if a student is sexually harassed or assaulted in Second Life? These and many other legal issues will need to be resolved (Bugeja, 2007).

Second life and most virtual worlds were not created for educational purposes. Second Life, nonetheless, is being adapted by educators forteaching and learning. Faculty can integratetext information in the form of note cards and use Web sites, content slides, video, and audio in addition to creating 3-D objects. However, many of the feat ures educat ors take for granted in Learning Management Systems do not exist in Second Life. For example, Learning Management Systems typically provide a grade book, an assignment drop box, asynchronous discussion tools, online surveys, and objective assessments. Additionally, Second Life is a random access environment thus giving instructors very little control over lesson sequencing.

Some of the Learning Management feat ures that are lacking in virtual worlds are beginning to be addressed. Efforts are underway to facilitate the use of Moodle, a free, open source Learning Management System, in Second Life. The set of tools being created has been named 'Sloodle'.

Sloodle is an Open Source project which aims to develop and share useful, usable, desirable tools for supporting education in virtual worlds, making teaching easier. Through engagement with an active community of developers and users, the Sloodle project hopes to develop sound pedagogies for teaching across webbased and 3D virtual leaming environments. Sloodle integrates the Second Life multi-user virtual environment and the Moodle learning-management system. (Sloodle.org, n.d.)

Sloodle has facilities for administering quizzes in virtual worlds, collecting assignments, and blogging. Much more work has yet to be done, however, to reach the faculty expectations of Learning Management systems.

\section{Future Implications}

Virtual worlds are truly a Pandora's Box for educators. While providing a plethora of new possibilities forteaching and learning, they also present a host of new challenges. Several topics regarding teaching and learning in virtual worlds need further exploration.

One such issue revolves around the faculty member's ability to adapt to a free format learning experience. Lectures, PowerPoint present ations, essay and multiple choice exams, even discussion boards are all tools where students' experiences are easily controlled and managed. When teaching in a virtual world, however, how do you control the learning environment? How do you create opport unities for learning and then apply a grade to learning of this type? Instructional design and assessment will have to be reconsidered in orderto accommodate and promote learning in virtual worlds.

Instructors have adapted to new technologies over the years. Digital project ors, audio, video, web sites, PowerPoint, and Learning Management Systems are all technologies which at one time presented their own set of challenges to educators. Can instructors adapt their teaching to meet the new challenges of virtual worlds? An evolution seems to have occurred where written lecture notes have moved from paper to PowerPoint to web pages. If the evolution continues and these same lecture notes are posted on a billboard in a virtual world, little has been gained. Can the typical college instructor throw away the lecture notes and truly rethink his/her approach to teaching? How much professional development will be necessary in order for instruct ors to effectively teach in this environment? How important a role will faculty learning communities or communities of practice play in the implementation of virtual worlds as an instructional technology? 
Another question to be explored is "where is the classroom?" Students, even in online classes, tend to associate "the classroom" with the physical campus that "sponsors" a class. Will there be a shift in perception if a class is created virtually? If physical and virtual locations are both used, with which will the students most identify? Will students be more at ease in online classes if there is an identifiable virtual classroom?

Many young children these days are quite comfortable in virtual worlds. As of August of 2007, a well known virtual world for children, Club Penguin, had 12 million registered users with 700,000 of those being paid subscribers. ("Walt Disney Acquires", 2007) Children are perfectly comfortable interacting with one another via computers. They daily play games and 'meet' each other online. They have experiences online that are part of their memory and their way of thinking about the world. How will this affect the way these children solve problems and communicate? What does the fut ure hold when children that are now using virtual worlds such as Club Penguin grow up and find themselves in a classroom?

Will avatars, a person's representation in a virtual world, play a role in how an instructorteaches and how a student learns? There is now the possibility that a teacher could be of any virtual sex, size, color, and even animal. Will this affect the engagement of the student? Will it be acceptable for a student's avatarto in no way resemble the student?

Many schools are creating virtual campuses that resemble their real campus. What are the benefits of re-creating the real campus versus creating a completely new campus? Schools are often proud of their identities. Many schools' web sites reflect these identifies through careful selection of colors, layout, fonts, pictures, etc. How will that identity be established in a virtual world?

\section{Future Research}

In an effort to further explore some of the questions posed previously; the authors of this paper are making plans to implement the use of virtual worlds in a Systems Analysis class. This research has the potential to address questions about accept ance of virtual worlds by moretechnologically literate faculty and students. This research could also address questions regarding student engagement in classes using virtual worlds.

The authors are exploring the idea of virtually recreating a common business process. One specific example being considered is a warehouse that is used to store and ship goods. Goods flow into the warehouse and are stored in bins and rows. As orders are received from customers, goods flow out of the warehouse and onto trucks for shipping. Students will use the steps in the systems development lifecycle to design and build a computer system to manage the warehouse. As part of their information gathering, students will have the opport unity to observe the processes taking place in the virtual warehouse. Additionally, the students will interview the avatars working in the warehouse. This research is currently in the earliest stages of consideration.

\section{Conclusion}

Virtual worlds represent an environment wherein educators can implement student-centered teaching pedagogies. Virtual worlds promote immersive, deep, authentic, active, and constructivist learning. The use of generative 3-D construction tools and scripting languages coupled with the enhanced sense of presence in 3-D environments significantly expands the repert oire of educational activities available to instructors and students. The enhanced sense of social interaction promotes the development of collaborative efforts to complete course tasks as well as the development of student learning communities. Costs, accessibility issues, legal issues, and increased development time remain the primary forces holding institutions back from taking advantage of this resource. 
A 2003 article in The Economist summarized the fut ure of technology:

Far from being over, the computer and telecoms revolution that created the internet has barely begun. These technologies will change almost every aspect of our lives - private, social, cultural, economic and political. In some areas, the changes may be marginal, but in most they will be profound, and unprecedented. This is because new electronictechnologies deal with the very essence of human society: communication between people. More importantly, they look as if together they will be as pervasive and ubiquitous as electricity. ("Survey", 2003)

Virtual worlds are a part of that future. At present they may be perceived as the "wild-wild west" of technology. However, there were many people in the early 1980's that viewed the internet as being equally untamed. Virtual worlds have the potential to dramatically change our lives as educators. The evidence points to a fut ure where virtual worlds will alter how, what, when, and where we teach.

\section{References}

Antonacci, D., \& Moderass, N. (2005, February 16). Second Life: The educational possibilities of a massively multiplayer virtual world $(M M V W)$. Retrieved September 2, 2007, from http://connect.educause.edu/library/abstract/SecondLi feTheEducati/43821

Bugeja, M. (2007, September 14). Second thoughts about Second Life. The Chronicle of Higher Education, C1.

Calongne, C., \& Bayne, G. (8/22/07). Podcast: Using Second Lifefor immersive learning. Retrieved September 2, 2007, from http://connect.EDUCAUSE.edu/blog/gbayne/podcastusingsecondli/44967

EDUCAUSE Learning Initiative (ELI). (2006, June). Seven things you should know about virtual worlds. Retrieved on September 2, 2007, from http://connect.EDUCAUSE.edu/library/abstract/7ThingsYouShouldKnow/39392

Gartner Research. (2007, April 24). Gartner says 80 percent of active Internet users will have a "Second Life" in the virtual world by the end of 2011. Retrieved on September 4, 2007, from http://www.gartner.com/it/page.jsp?id=503861

Institutions and organizations in Second Life: Universities, colleges, and schools. (September, 2, 2007). Retrieved September 4, 2007, from http://simteach.com/wiki/index.php?title=Institutions and Organizations in Second Life\#UNIVERSITIES.2C COLLEGES .26_SCHOOLS

James, J. (October 9, 1997). Thinking in the future tense. Paper presented at the Lead ership Buffalo Conference, Buffalo, NY.

Kemp, J., \& Livingstone, D. (n.d.). Putting a second life "metaverse" skin on learning management systems. Whitepaper. Retrieved September 2, 2007 from http://www.sloodle.com/whitepaper.pdf

Kirkman, G. S., Cornelius, P. K., Sachs, J. D., \& Schwab, K. (2002). The global information technology report 2001-2002: Readiness for the networked world. New York, Oxford: Oxford University Press.

LaChapelle, N. (2007, July 18). EDUCAUSE CONNECT: Some foundations for Second Life pedagogy. Retrieved September 2, 2007, from http://connect.educause.edu/blog/HiredEd/some found ations forse/44785

Lombardi, M. (2007). Authentic learning for the $21^{\text {st }}$ Century: An overview. EDUCAUSE Learning Initiative. Retrieved September 2, 2007 from http://connect.educause.edu/library/abstract/AuthenticLearning for/39343

Memberships, land, and pricing. (2007). Retrieved November 10, 2007, from http://secondlife.com/whatis/pricing.php . 
Metaverse RoadMap Glossary. (2007). Retrieved March 13, 2008, from http://metaverseroadmap.org/inputs4.html\#glossary .

Moore, A., Fowler, S., \&W atson, C. (2007, September/October). Active learning and technology: Designing change for faculty, students, and institutions. EDUCAUSE Review, 42(5), 42-61.

New Media Consortium \& the EDUCAUSE Learning Initiative (ELI). (2007). 2007 Horizon Report. Retrieved September 2, 2007, from http://www.nmc.org/horizon

Polka, W. (2001). Facilitating the transition from teacher centered to student centered instruction at the university level via constructivist principles and customized learning plans. Educational Planning, 13(3), 55-61.

Polka, W.S. (1999). Managing the dynamic forces that will influence the curriculum in the new millennium. Educational Planning, 11(4).

Roush, W. (2007, July/August). Second earth. Technology Review, 39 - 48.

Serious Games Summit Keynote: You can (not) be serious. (2006, March 20). Retrieved September 21, 2007, from http://www.gamasutra.com/features/20060320/carless 01.shtml

Sloodle (n.d.) Retrieved September 29, 2007, from http://www.sloodle.org/

Survey: Digital dilemmas. (2003, January). The Economist, 366(8308), S3-S5. Retrieved November 26, 2007, from ABI/INFORM Complete database. (Document ID: 281360411).

The Walt Disney Company acquires club penguin. (2007, August 1). Retrieved November 7, 2007 from http://clubpenguin.com/press/070801-the-walt-disney-company.htm.

\section{Biographies}

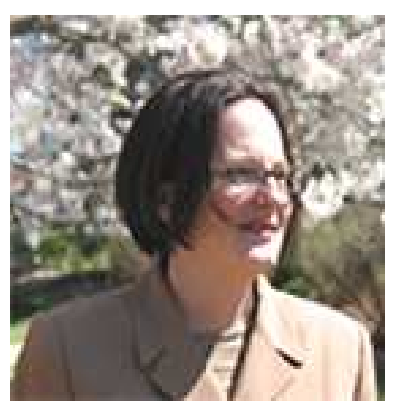

Stacy Kluge is currently employed as an Instructional Designer in the Center for Excellence in Teaching at Georgia Southern University. Previously Stacy was employed as an Assistant Professor in the School of Information Technology at Macon State College. She received her M Ed in Instructional Technology from Georgia College and State University in 1999 and is currently pursuing an Ed. D. Higher Education Leadership at Georgia Southem University. Her research interests center around the Scholarship of Teaching and Learning.

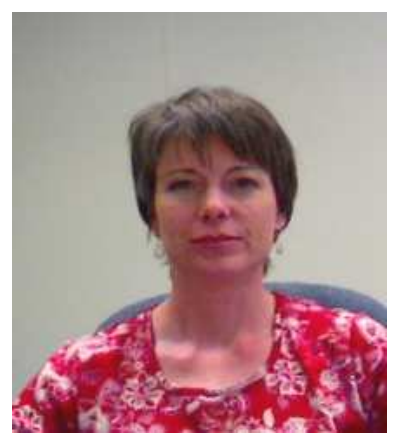

Elizabeth Riley is an Associate Professor in the School of Information Technology at Macon State College. She holds a M.B.A. from Georgia College and State University. She has 15 years experience as an Information Technology professional and has taught programming and web design courses for the last six years. She has an interest in the educational opport unities offered by virtual worlds. 